\title{
ROLE OF DIAGNOSTIC LAPAROSCOPY IN CHRONIC ABDOMINAL PAIN
}

\author{
R. G. Naniwadekar1, Madhavendra Varadraj Kabra², Mahesh S. Reddy ${ }^{3}$ \\ ${ }^{1}$ Associate Professor, Department of General Surgery, Krishna Institute of Medical Sciences, Karad. \\ ${ }^{2}$ Resident, Department of General Surgery, Krishna Institute of Medical Sciences, Karad. \\ ${ }^{3}$ Resident, Department of General Surgery, Krishna Institute of Medical Sciences, Karad.
}

\section{ABSTRACT}

\section{OBJECTIVE}

To assess the diagnostic and therapeutic role of laparoscopy in patients with unexplained chronic abdominal pain.

\section{METHODS}

During the period of 2 years from May 2013 to May 2015, 50 cases were studied in Krishna Institute of Medical Sciences, Karad. Soon after admission the data was recorded according to the proforma. Chief complaints of majority of patients were pain in abdomen lasting for months, on and off vomiting, fever and distension. Detail history was taken followed by general and physical examination. This project by its very nature involved the use of hematological, biochemical, pathological and microbiological investigations, radiological investigations including ultrasonography, CT and MRI; and also expert surgical management including laparoscopy. An informed consent was taken. Patients were treated in the same hospital in the span of study and followed till discharge. First followup after 1 week and second followup after 1 month.

\section{RESULTS}

1. Maximum age incidence in patients of chronic abdomen was in the age group of 31-40 years, while pathology was found highest in 41-50 years.

2. Females outnumbered males in this study.

3. Most common causes of chronic abdomen were abdominal Koch's and adhesions.

4. Abdominal Koch's was the most common cause of intestinal obstruction and recurrent chronic abdominal pain.

5. Laparoscopy assisted surgery was done in $48 \%$ of the cases, while diagnostic and therapeutic laparoscopy was done in $26 \%$ of the cases.

6. Conversion rate of laparoscopy to laparotomy in chronic abdomen was in 4 cases, i.e. $8 \%$.

7. Complications occurred in 5 cases $(10 \%)$ of chronic abdomen during laparoscopy of which 3 were postoperative and 2 were intraoperative.

8. Nine patients had no obvious pathology.

\section{CONCLUSION}

Diagnostic laparoscopy is a safe, feasible and accurate tool for management of patients with chronic abdomen.

\section{KEYWORDS}

Diagnostic Laparoscopy, Abdominal Pain.

HOW TO CITE THIS ARTICLE: Naniwadekar RG, Kabra MV, Reddy MS. Role of diagnostic laparoscopy in chronic abdominal pain. J. Evolution Med. Dent. Sci. 2016;5(17):859-863, DOI: 10.14260/jemds/2016/198

\section{INTRODUCTION \\ Chronic Abdominal Pain}

Pain is derived from the Latin word "Poena," which means penalty or punishment. Chronic abdominal pain is defined as a condition in which the patient complains of a long term persisting pain that lasts for several months ( $>6$ months) since the irritation of pain.[1] Chronic abdominal pain has a variety of causes which requires prompt treatment, but all of them do not require exploration. Chronic Abdominal Pain (CAP) is a common complaint of patients seeking a primary care physician, it is a leading reason for referral to a gastroenterologist and the 4th frequent chronic pain syndrome in the general population, it represent about $13 \%$ of all surgical admissions. ${ }^{[2]}$ Exploratory laparotomy has several disadvantages apart from chances of negative laparotomy.

Financial or Other, Competing Interest: None.

Submission 14-01-2016, Peer Review 10-02-2016,

Acceptance 15-02-2016, Published 29-02-2016.

Corresponding Author:

Dr. Madhavendra Varadraj Kabra,

IHR Hostel, KIMS, Karad.

E-mail: drmaddy7888@gmail.com

DOI: $10.14260 /$ jemds/2016/198
It has an abdominal incision which makes the patients less ambulatory due to pain, also it causes respiratory discomfort. It increases chances of wound infection, paralytic ileus. As a solution to these problems diagnostic laparoscopy has become very much popular now a days.

\section{Diagnostic Laparoscopy}

Laparoscopy is derived from the Greek word "lapara" meaning flank or loin and "skopein" meaning to see, view and examine. Diagnostic Laparoscopy (DL) is minimally invasive surgery for diagnosis of intra-abdominal diseases. The procedure enables direct inspection of large surface areas of intra-abdominal organs, facilitates biopsies and obtaining cultures and aspirates, allows the use of laparoscopic ultrasound and makes therapeutic intervention possible. DL has become an integral part of general surgical procedures with recent advancements in laparoscopic technology. It minimizes surgical trauma in chronically ill patients with chronic abdominal disorders resulting in a better outcome and making short stay possible. 
Diagnostic laparoscopy is an important tool in final minimally invasive exploration for patients with chronic abdominal disorders, the diagnosis of which remains uncertain despite employing the requisite laboratory and noninvasive imaging investigations.

Diagnostic laparoscopy can be used to evaluate several types of liver diseases including discrete masses, diffuse diseases, unexplained portal hypertension, abdominal tuberculosis, congenital anomalies, non-palpable testis, various types of malignancies etc. Diagnostic laparoscopy is absolutely contraindicated in coagulation defects, bleeding disorders, major cardiac and respiratory disorders.

\section{This study,}

1. Helps us to understand what diagnostic laparoscopy is.

2. Describes how laparoscopy helps to find out what the problem is.

3. Explains what complications can occur with the procedure.

\section{MATERIALS AND METHODS}

The study was conducted in Krishna Institute of Medical Sciences University, Karad, to survey and diagnose undiagnosed cases of chronic abdominal pain by laparoscopy in surgical wards. During the period of 2 years from May 2013 to May 2015, 50 cases were studied. Soon after admission, the data was recorded according to the proforma. Chief complaints of majority of patients were pain in abdomen lasting for months, on and off vomiting, fever and distension. Detail history was taken followed by general and physical examination. This project by its very nature involved the use of haematological, biochemical, pathological and microbiological investigations, radiological investigations including ultrasonography, CT and MRI; and also expert surgical management including laparoscopy. An informed consent was taken. Patients were treated in the same hospital in the span of study and followed till discharge. First followup after 1 week and second follow up after 1 month.

\section{Patient Selection Criteria}

\section{Inclusion Criteria}

1. All age groups.

2. Both the sexes.

3. Patients presenting with undiagnosed chronic pain abdomen.

4. Patients who had undergone previous surgeries.

\section{Exclusion Criteria}

1. Patients with acute abdomen.

2. Patients unfit for GA.

3. Patients with bleeding disorders.

4. Patients with severe cardiac and respiratory problems.

5. Patients of gynaecological origin.

6. Patients where laparotomy was clearly required.

\section{PROCEDURE OF DIAGNOSTIC LAPAROSCOPY \\ Preoperative Preparation}

Complete history was taken and thorough physical examination was performed in all the patients giving stress on the duration, site of pain, previous history of any surgery and other related problems. In all patient's routine investigations like haemoglobin, total count, differential count, erythrocyte sedimentation rate, bleeding time, clotting time, blood sugar, blood urea, serum creatinine, sodium, potassium, urine routine and microscopy, chest X-ray, electrocardiogram and ultrasonography was done. Liver function tests, blood grouping and prothrombin time was done in selected cases. CT and MRI was done in selected cases. Physicians and gynaecologists opinion was taken if needed. Informed risk consent was taken from the patient and their relatives after explaining the procedure, the risk and its complications.

Consent was taken if any special procedure was planned and also regarding possibilities of conversion of laparoscopy to laparotomy. The abdomen and parts were shaved. All patients were kept nil orally after $10 \mathrm{pm}$ the previous night, enema and rectal suppositories were given where required. All patients were put under antibiotic cover and Ryle's tube and urinary catheter was inserted. All patients were operated under general anaesthesia.

\section{Operative Technique for Diagnostic Laparoscopy}

In chronic abdomen after taking due consent of patients, they were posted for diagnostic laparoscopy. Sites of ports were decided depending on findings of clinical examination. Usually two ports were used. The third port was optional. All abdominal organs were carefully explored to confirm or exclude the diagnosis. Exploration usually started in the right lower quadrant but approach was changed whenever necessary on findings of clinical examination. Free fluid in abdomen was sent for cytology, bacteriology and culture. Peritoneal lavage was given whenever necessary. Operative and Therapeutic Laparoscopy was undertaken whenever indicated and if possible, through additional ports. Sites of ports were decided according to pathology detected on diagnostic laparoscopy. Operative procedures were performed wherever necessary. Suction irrigation was done wherever necessary and the biopsy specimens were sent for histopathology.

\section{Post-operative Management}

All patients were kept nil orally for 24 hours at times and if required for 48 hours. Patients were monitored with pulse, blood pressure and temperature charting. Injectable antibiotics and analgesics were used accordingly. Ryle's tube and urinary catheter were removed depending upon the condition. Most of our patients who were treated laparoscopically were discharged in 4 days. The patients who had to undergo laparotomy were discharged in 10 days depending upon the condition. Appropriate treatment was started once the diagnosis was established. All patients after discharge were followed up in OPD after 1 week and if required were asked to follow accordingly.

\section{STATISTICAL ANALYSIS}

The records of the 50 patients who were referred for elective diagnostic laparoscopy to the Department of General Surgery at Krishna Institute of Medical Sciences University Hospital, Karad, were reviewed prospectively for demography, clinical presentation and laboratory tests, imaging investigations, indications and findings in diagnostic laparoscopy as well as biopsy results. The accuracy and the impact of the procedure on the outcome were evaluated. 
Following were the Observations

\begin{tabular}{|c|c|c|}
\hline $\begin{array}{l}\text { Age Group } \\
\text { (In years) }\end{array}$ & No. of Cases & Percentage (\%) \\
\hline $0-10$ & 0 & $0 \%$ \\
\hline $11-20$ & 4 & $8 \%$ \\
\hline $21-30$ & 14 & $28 \%$ \\
\hline $31-40$ & 15 & $30 \%$ \\
\hline $41-50$ & 14 & $28 \%$ \\
\hline $51-60$ & 3 & $6 \%$ \\
\hline Total & 50 & $100 \%$ \\
\hline
\end{tabular}

From the above observations, it is clear that the maximum number of patients were of 31 to 40 years ( 15 of 50 patients, i.e. $30 \%$ ). Least number of patients were from age group of more than 50 years ( 3 of 50 patients, i.e. $6 \%$ ). Age group of 21 to 30 and 41 to 50 constituted 14 cases each (28\%), 11 to 20 years had 4 cases (8\%) and none from below 10 years.

\begin{tabular}{|c|c|c|}
\hline Sex & $\begin{array}{l}\text { No. of Cases } \\
\text { Percentage }\end{array}$ & Percentage (\%) \\
\hline Male & 24 & 48 \\
\hline Female & 26 & 52 \\
\hline Total & 50 & 100 \\
\hline
\end{tabular}

Above table suggests that number of female patients of chronic abdomen were more than that of male patients due to increased number of open surgeries in females.

\begin{tabular}{|c|c|c|}
\hline Pathology & $\begin{array}{l}\text { No. of } \\
\text { Cases }\end{array}$ & Percentages (\%) \\
\hline Abdominal Koch's & 12 & $29.26 \%$ \\
\hline $\begin{array}{c}\text { Adhesive Intestinal } \\
\text { obstruction }\end{array}$ & 11 & $26.82 \%$ \\
\hline $\begin{array}{c}\text { Meckel's } \\
\text { diverticulum }\end{array}$ & 6 & $14.63 \%$ \\
\hline $\begin{array}{c}\text { Retroperitoneal } \\
\text { lymphadenopathy }\end{array}$ & 3 & $7.31 \%$ \\
\hline $\begin{array}{l}\text { Hepatico omento } \\
\text { band }\end{array}$ & 1 & $2.43 \%$ \\
\hline Appendicitis & 4 & $9.75 \%$ \\
\hline Scar adhesions & 3 & $7.31 \%$ \\
\hline Ladd's band & 1 & $2.43 \%$ \\
\hline Total & 41 & $100 \%$ \\
\hline
\end{tabular}

In this study, it is clear that the most common cause of chronic abdomen was abdominal Koch's, i.e. 12 of 50 cases (29.26\%), followed by adhesive intestinal obstruction due to adhesions, i.e. 11 (26.82\%) followed by Meckel's diverticulum i.e. $6(14.63 \%)$ followed by appendicitis, i.e. 4 cases $(9.75 \%)$ followed by retroperitoneal lymphadenopathy and scar adhesions accounting for 3 cases each (7.31\%) followed by hepatic omento bands and lastly congenital anomaly Ladd's band for a single case $(2.43 \%)$ each. Nine patients had no obvious pathology.

\begin{tabular}{|c|c|c|}
\hline Management & $\begin{array}{c}\text { No. of } \\
\text { Cases }\end{array}$ & Percentage (\%) \\
\hline $\begin{array}{c}\text { Lap assisted } \\
\text { surgery }\end{array}$ & 24 & $48 \%$ \\
\hline $\begin{array}{c}\text { Diagnostic and } \\
\text { therapeutic } \\
\text { laparoscopy }\end{array}$ & 13 & $26 \%$ \\
\hline $\begin{array}{c}\text { Negative } \\
\text { laparoscopy }\end{array}$ & 9 & $18 \%$ \\
\hline $\begin{array}{c}\text { Laparotomy } \\
\text { conversion) }\end{array}$ & 4 & $8 \%$ \\
\hline Total & $\mathbf{5 0}$ & $\mathbf{1 0 0 \%}$ \\
\hline $\begin{array}{c}\text { Table 4: Management Policies of } \\
\text { Patients with Chronic Abdomen }\end{array}$ \\
\multicolumn{2}{|r}{}
\end{tabular}

In our 50 cases of chronic abdomen, laparoscopic assisted surgery was done in 24 patients, i.e. $48 \%$. Diagnostic and therapeutic laparoscopy including cytology, biopsy and culture was done in 13 patients, i.e. $26 \%$. In 9 patients the laparoscopy was with no findings (negative laparoscopy), i.e. $18 \%$. Four cases $(8 \%)$ required exploratory laparotomy; in two patients there was accidental injury to the bowel in small bowel obstruction and the others were mass in right iliac fossa secondary to tuberculosis and Ladd's band.

\begin{tabular}{|c|c|c|}
\hline Complications & $\begin{array}{l}\text { No. of } \\
\text { Cases }\end{array}$ & Percentage (\%) \\
\hline Major vessel injury & 0 & 0 \\
\hline Bowel injury & 2 & $4 \%$ \\
\hline Wound gaping & 0 & 0 \\
\hline Shoulder pain & 0 & 0 \\
\hline $\begin{array}{c}\text { Subcutaneous } \\
\text { emphysema }\end{array}$ & 1 & $2 \%$ \\
\hline Post site infection & 2 & $4 \%$ \\
\hline Omental prolapse & 0 & 0 \\
\hline Post site hernia & 0 & 0 \\
\hline Total & 5 & $10 \%$ \\
\hline \multicolumn{3}{|c|}{$\begin{array}{c}\text { Table 5: Incidence of Laparoscopic } \\
\text { Complications in Cases of Chronic Abdomen }\end{array}$} \\
\hline
\end{tabular}

Complications related to laparoscopy in our study were observed in 5 out of 50 cases. Two of them were related to bowel injury and post site infection, i.e. (4\%) each, while the remaining one was related to subcutaneous emphysema, i.e. (2\%).

\section{RESULTS}

1. Maximum age incidence in patients of chronic abdomen was in the age group of 31-40 years, while pathology was found highest in 41-50 years.

2. Females outnumbered males in this study.

3. Most common causes of chronic abdomen were abdominal Koch's and adhesions.

4. Abdominal Koch's was the most common cause of intestinal obstruction and recurrent chronic abdominal pain.

5. Laparoscopy assisted surgery was done in $48 \%$ of the cases, while diagnostic and therapeutic laparoscopy was done in $26 \%$ of the cases.

6. Conversion rate of laparoscopy to laparotomy in chronic abdomen was in 4 cases, i.e. $8 \%$. 
7. Complications occurred in 5 cases $(10 \%)$ of chronic abdomen during laparoscopy of which 3 were postoperative and 2 were intraoperative.

8. Nine patients had no obvious pathology.

\section{DISCUSSION}

Though first laparoscopy in dog was done in 1901 by George Kelling and in humans in 1910 by Jacobeus, surgeons have been slowly adopting laparoscopy as a diagnostic modality. The growing experience with therapeutic laparoscopy has resulted in development of diagnostic laparoscopy. In cases of diagnostic uncertainty or ambiguities in radiological tests laparoscopy may exclude or confirm a pathological finding or diagnosis. It can also help a surgeon to plan appropriate treatment modality and also avoid unnecessary laparotomies. $[3,4,5,6,7,8]$

\section{Age Incidence}

In our study, patients included were of all ages. We grouped them as 0-10 years, $11-20$ years, $21-30$ years, $31-40$ years, 41 50 years and more than 50 years. We found that maximum patients of chronic abdomen were from age group of 31-40 years, i.e. 15 out of 50 cases (30\%). Next to follow was age group of 21-30 years and 41-50 years with 14 cases each (28\%). Age group 11-20 years had 4 cases $(8 \%)$, more than 50 years had 3 cases $(6 \%)$ and none were reported from $0-10$ years.

According to Gamal I. Moussa and Amal E. Mahfouz.[9] diagnostic laparoscopy was done in 56 patients presenting with CAP, out of which the mean age was around 28 years and the conversion of diagnostic procedure to operative laparoscopy was $64.3 \%$, which closely correlates with our study. According to Gamal I. Moussa and Amal E. Mahfouz diagnostic laparoscopy was done in 56 patients presenting with CAP, out of which the mean age was around 28 years and the conversion of diagnostic procedure to operative laparoscopy was $64.3 \%$, which closely correlates with our study.

\section{Sex Distribution}

Among 50 patients of chronic abdomen, 26 were females (52\%) and 24 were males (48\%). More number of females is due to the number of abdominal operations they underwent due to caesarean sections and hysterectomy. According to Gamal I. Moussa and Amal E. Mahfouz.[9], diagnostic laparoscopy was done in 56 patients presenting with CAP, out of which females $(71.3 \%)$ were more than males, the diagnosis being adhesions, TB and chronic appendicitis.

\section{Incidence of Various Pathologies in Chronic Abdomen}

We did not include gynaecological cases in our study. Abdominal Koch's was the most frequent cause in our study, i.e. 12 out of 41 cases (29.26\%). Of these 8 (66.66\%) were males and 4 (33.33\%) were females. Age groups having abdominal Koch's commonly were more than $41-50$ years, i.e. 7 cases. The second common cause of chronic abdominal pain was adhesive intestinal obstruction with 11 cases (26.82\%), maximum were from age group of 21-30 years, i.e. 6 cases. The third common cause in our study was Meckel's diverticulum with 6 cases $(14.63 \%)$ with maximum from 21 to 30 years, i.e. 3 cases. Appendicitis had 4 cases (9.75\%), while scar adhesions and retroperitoneal lymphadenopathy accounted 3 cases $(7.31 \%)$ each and hepatic omentum bands and Ladd's band had 1 case $(2.43 \%)$ each. Nine patients had no obvious pathology.

According to Prafull K. Arya and K.J.B.S Gaur.[10] Prospective study of 49 patients who underwent diagnostic laparoscopy for chronic abdominal pain, findings included (Including histopathology) abdominal tuberculosis in 14, postoperative adhesions in 4. Present study shows a diagnostic rate of $90 \%$ in patients with lower abdominal pain. Therapeutic laparoscopy had a role in many of these patients. This correlates with our study.

According to Malik AM, Talpur KA, Soomro AG, Qureshi JH.[11] a total of 133 patients with vague abdominal symptoms were studied out of which 109 (80\%) patients were diagnosed abdominal laparoscopy. The common symptoms were pain abdomen, generalized weakness, changing bowel habits. Various TB lesions were detected on laparoscopy. Biopsy of the specimens proved TB in those patients. Patients were saved from unnecessary laparotomies and managed on antitubercular drugs. This correlates with our study.

\section{Laparoscopic management of chronic abdomen}

In our study, 50 cases of undiagnosed chronic abdominal pain were studied out of which laparoscopic surgery was done in 24 patients (48\%), diagnostic and therapeutic laparoscopy in 13 (26\%), negative laparoscopy in 9 (18\%) and conversion into laparotomy in 4 patients $(8 \%)$. The laparotomy was due to accidental injury to the small bowel during dissection in 2 patients and the others were mass in right iliac fossa in a suspected case of TB and Ladd's procedure. According to Paajanen Hannu MD, Julkunen Kristiina MD, Waris Heidi MD.[12] 72 patients were studied out of which adhesiolysis was done in 61 patients, appendicectomy in 1 and 6 had no abnormality. The complication rate was in 4 patients due to injury to the bowel and bleeding, which were later on converted into laparotomy. This study closely correlates to our study. Nagy and James.[3] yielded a diagnostic accuracy in 37 out of 42 patients in their study and avoided unnecessary laparotomy. Similarly results were shown by studies done by Shrenk. ${ }^{[13]}$ in which he reported 38 out of 46 patients and Karl Miller.[14] in which he diagnosed 53 out of 59 patients.

\section{Complications of laparoscopy in chronic abdomen}

In 50 cases of chronic abdomen, we studied complications were seen in 5 patients $(10 \%)$. In 2 patients, there was accidental bowel injury during dissection and adhesiolysis. Two patients had infraumbilical port site infection, which was managed on dressing and one had subcutaneous emphysema. According to Paajanen Hannu MD, Julkunen Kristiina MD, Waris Heidi MD, 72 patients were studied out of which 8 patients (11\%) had complications. It included bowel injuries, perforation of urinary bladder and post site infections. This closely correlates with our study.

\section{CONCLUSION}

In conclusion, diagnostic laparoscopy is a safe, feasible and accurate tool for management of patients with chronic abdomen. It allows the doctor to directly look at the organs of abdomen in order to diagnose the problem. It is useful in patients in whom the diagnosis and the extent of the disease 
are equivocal. Even negative laparotomies can be avoided using DL. Therapeutic laparoscopy can be accomplished in a majority of patients where laparotomies are not possible due to some reason. It can also help in laparoscopy assisted surgeries thereby avoiding laparotomies and its complications. Where laparotomies are indicated DL can decide the site of incision. It should be reserved for those situations after non-invasive method fail to make a diagnosis. DL has many advantages of shorter hospital stay, early recovery and good cosmesis. Laparoscopy should be performed as an early investigative procedure in these patients, because "Diagnosis should precede treatment whenever possible" as quoted by Hutchison's Clinical methods.

\section{REFERENCES}

1. Pain Management: Practical Guide to Clinicians, 6th edition. Richard S Weiner. ISBN 0-8493-0926-3, Thienhaus O; Cole BE (2002). "Classification of Pain."

2. John RD, Gary WV and Laurie H. What could be causing chronic abdominal pain? Postgraduate Medicine 1999;106(3):1-8.

3. Alexander G Nagy, David James. Diagnostic laparoscopy. AJS 1989;157:490-493.

4. Debanto JR, Varilek GW. What could be causing chronic abdominal pain? Anything from common peptic ulcers to uncommon pancreatic trauma, Post Graduate Medical, September 1999;106(3):141-146.
5. Fred M Howard. "The role of laparoscopy in chronic pelvic pain: promise and pitfalls." Obstetrical and Gynaecological Survey, 1993;48(6):357-387.

6. Jonathan Sacker, MD. Diagnostic laparoscopy in nonmalignant disease. Surgical Clinics of North America. October 1992;72(5):103-104.

7. Kratner KF, Maurer M. The value of imaging techniques in the diagnosis of non-specific abdominal pain in young patients. Aktwelle Radiol. July 1992;2(4):234-238.

8. Paul H Sugarbaker, Bernards, Blood et al. Pre-operative laparoscopy in diagnosis of chronic abdominal pain. The Lancet 22:442-444.

9. Gamal I Moussa, Amal E Mahfouz. Role of laparoscopy in the management of unexplained chronic abdominal pain. Egyptian Journal of Surgery, Jan 2004; Vol (23), No 1.

10. Prafull K Arya and Gaur KJBS. "Laparoscopy, a tool in diagnosis of lower abdominal pain." Indian J Surg, Aug 2004;66(4):216-220.

11. Malik AM, Talpur KA, Soomro AG, et al. "Yield of diagnostic laparoscopy in abdominal tuberculosis." Surg Endosc Percutan Tech 2011 Jun 21(3):191-3.

12. Hannu Paajanen, Kristina Pulkunen and Heidi Waris. "Laparoscopy in chronic abdominal pain." J Clin Gastroenterol, Feb 2005;39(1,2):110-114.

13. Peter Schrenk, Rudolf W, et al. Diagnostic laparoscopy a survey of 92 patients. AJS. Oct 1994;168:348-351.

14. Karl Miller, Edith Mayer, et al. The role of laparoscopy in chronic and recurrent abdominal pain. AJS. October 1996; Vol. 172:353-357. 